\section{Consumer Perceptions, Attitudes, and Purchase Behavior with Landscape Plants during Real and Perceived Drought Periods}

\author{
Melinda Knuth ${ }^{1}$ \\ Department of Horticultural Sciences, Texas A\&M University, 2133 TAMU, \\ College Station, TX 77843
}

Bridget K. Behe ${ }^{2,4}$

Department of Horticulture, Michigan State University, 1066 Bogue Street, East Lansing, MI 48824-1325

Charles R. Hall ${ }^{3}$

Department of Horticultural Sciences, Texas A\&M University, 2133 TAMU, College Station, TX 77843

Patricia T. Huddleston ${ }^{2}$

Department of Advertising and Public Relations, Michigan State University, 404 Wilson Road, East Lansing, MI 48824

\section{R. Thomas Fernandez ${ }^{2}$ \\ Department of Horticulture, Michigan State University, 1066 Bogue Street, East Lansing, MI 48824-1325}

Additional index words. online survey, water conservation

\begin{abstract}
In the coming decades, no natural resource may prove to be more critical to human health and well-being than water. There is abundant evidence that the condition of water resources in many parts of the United States is deteriorating. In some regions of the country, the availability of sufficient water to meet growing domestic uses, and the future sufficiency of water to support the use of landscape plants where we live, work, and play is in doubt. Conservation through water efficiency measures and water management practices may be the best way to help resolve water problems. Yet, consumer perceptions and attitudes and behavior toward water conservation may differ widely, particularly in the presence of drought. This study sought to add to the current horticulture and water conservation literature by exploring consumer attitudes and behavior during real and perceived drought situations, especially in terms of their landscape purchases and gardening/landscaping activities. Study findings could better inform educational programs and marketing strategies, helping to ensure the future demand of Green Industry products and services. With a national sample of 1543 subjects, an online survey tool was used to classify respondents into categories based on whether they accurately perceived if the region in which they lived was experiencing drought. We hypothesized that consumers were heterogeneous in their attitudes and behavior regarding plants and water conservation, depending on their real and perceived drought situations, and that their attitudes affected their behavior regarding plant purchases. Results confirmed this hypothesis. Attitudes and behaviors for those who correctly perceived they were in drought were different from those who correctly perceived they were not in drought, as well as those who incorrectly did not perceive they were in an actual drought.
\end{abstract}

Received for publication 7 Sept. 2017. Accepted for publication 13 Nov. 2017.

Funding for this study was provided by USDA SCRI Clean WateR ${ }^{3}$ - Reduce, Remediate, Recycle Grant Number 2014-51181-22372; USDA NIFA Hatch Projects MICL 02085, MICL 1011569, and TEX0-1-7051; Michigan State University AgBioResearch, and MSU Project GREEN and Texas A\&M AgriLife Research.

${ }^{1}$ Doctoral Student.

${ }^{2}$ Professor.

${ }^{3}$ Professor and Ellison Chair.

${ }^{4}$ Corresponding author. E-mail: behe@msu.edu.
Water is essential for all life, including plants, and $\approx 40 \%$ to $70 \%$ of U.S. water is used in urban areas (Spinti et al., 2004; St. Hilaire et al., 2008). Springer (2011) reported that the average U.S. household used $\approx 69$ gallons of water per capita daily in 2006 . Globally, nearly $40 \%$ of food resources come from irrigated land (Somerville and Briscoe, 2001). Water resources will become scarcer as the world population increases (Springer, 2011), which will have an impact on how and where we use water. If consumer attitudes and behaviors severely reduce or eliminate landscape water use, it will have a widespread and detrimental effect on the Green Industry. The current climate is ideal to discover the role of consumer attitudes and perceptions of water use and source with regard to landscape plants. These discoveries can be used to better inform educational and marketing efforts to help sustain the green industry during drought periods.

Household water usage in the United States is greatly affected by water shortages. The U.S. Geological Survey estimates domestic water usage every 5 years. In 2010 (last survey administered), the total freshwater withdrawals were estimated to be 355 billion gallons per day, which represented $86 \%$ of total withdrawals (Maupin et al., 2014). More than 42,000 million gallons of water per day is drawn for public water usage for 286 million people. Public water is any water drawn for domestic, commercial, and industrial needs. Of public water, domestic water usage represents $57 \%$ and is classified as all water used for nonagricultural or industrial purposes excluding all water not used in households. Sixty-three percentage of the water drawn for public supply was from surface sources, such as rivers and lakes, whereas $37 \%$ was from groundwater.

The Columbia Water Project (Alfredo, 2016) brings to light much of the groundwater deficit the United States is experiencing. In the states of Arizona, California, Illinois, Indiana, Iowa, Kansas, Minnesota, North Dakota, Oklahoma, South Dakota and parts of Texas, Michigan, and Wisconsin, there is a Normalized Deficit Cumulated (NDC) $>5$. $\mathrm{NDC}$ is the maximum cumulative water deficit between supply and demand as a ratio to its average annual precipitation (Alfredo, 2016). The NDC is important because it shows the level of replenishment of groundwater resources vs. annual withdrawal. Groundwater removal is increasing in states that have high multiyear drought such as Arizona, California, and Texas. In those areas, groundwater levels are falling.

Recent work indicates that attitudes and behavior toward potable water supplies have changed somewhat because of greater social awareness and increasingly widespread exposure to drought conditions (Beal et al., 2013). Education about and adoption of sustainable water use practices will ensure an adequate supply of quality landscape water while conserving water sources for human and ecosystem services (Beal et al., 2013). It is important to analyze consumer perceptions of water scarcity vs. actual water scarcity because past literature has shown that there is a deficit in homeowner knowledge concerning their actual water usage. Perceptions may, and often do, differ from reality and should be analyzed separately. By stepping into the dialogue with more evidence of behavioral differences among those who perceive to be in drought, and those who do not, we can contribute valuable insight to educators and marketers to reach consumers before, and during, drought. Reaching 
individuals in a timely manner is particularly important for plant producers and retailers who desire to merchandise more droughttolerant plants and water-saving practices to their clientele.

\section{Drought Influences}

There is research reported in the literature that provides a basis for understanding how consumers view water conservation, especially related to their landscape. However, the evidence is limited to a few droughtprone states. Little is known about consumer behavior during real and perceived periods of drought, especially with respect to plant production water source and water use in the landscape.

Attitude and behavioral studies have documented drought water usage for different regions of the United States. Boyer et al. (2015) found that when California households experienced drought conditions locally, outdoor water usage did not change substantially but indoor water usage did. Fan et al. (2017) showed that Las Vegas, NV, homeowners behaved similarly by landscaping homes to look more like their neighbors, which created community amenities, cultural values, and a sense of place. Homeowners who gain personal satisfaction from lawn aesthetics (often to impress neighbors) tend to irrigate more frequently (Fan et al., 2017). Incorporation of drought-tolerant plants into the landscape has been identified as a promising strategy to mitigate regional water constraints, but this will require attitudinal and behavioral changes within the communities (Fan et al., 2017).

Fan et al. (2017) discovered that a majority $(77 \%)$ of homeowner respondents were more concerned with long-term droughts (or dry periods) than frequent heavy rains. Household water consumption did change under different precipitation conditions, which demonstrated that some homeowners were aware of their changing drought conditions (Gregory and Leo, 2003). This was explained as "personal involvement," with an awareness of drought conditions leading to altered behavior (Espey et al., 1997). Awareness of local environmental issues increased the perception of personal involvement resulting in altered habits and lower water consumption rates (Gregory and Leo, 2003). Consumers' attitudes and water use during nondrought conditions can be key indicators of garden water use and plant maintenance (Syme et al., 2004). Two groups in that study, the Committed and Mainstream Environmentalists, tended to have smaller household sizes as compared with Occasional or Nonenvironmentalists. Nonenvironmentalists had a lower mean household income as compared with the other three groups. Nonenvironmentalists were less likely to believe helping the environment was socially acceptable and desirable (Gilg and Barr, 2006). This was correlated with their water usage and conservation practices.

\section{Residential Water Use}

Hayden et al. (2015) reported that as much as $70 \%$ of urban water is used to for maintaining landscape plantings. Although the reasons are various and unclear, water use appears to be important because of aesthetic and recreational priorities which are deeply ingrained in all lifestyles (Beal et al., 2013; Fan et al., 2017; Gregory and Leo, 2003; Springer, 2011; Syme et al., 2004). Water fills a basic physiological need for plants, and the plants then fill a psychological need for homeowner identity, status, and symbolic social competition (Seyranian et al., 2015). Homeowners who perceive that their landscape affects the resale value of their home tended to use more water annually, as did persons who spent more time outdoors (Syme et al., 2004). Shade trees in urban areas can offset heat for an average of $3.6 \mathrm{kWh} \cdot \mathrm{d}^{-1}$ or $\approx 30 \%$ energy savings per day (Akbari, 2005). Maintaining lush landscapes has also been heavily linked to environmental benefits such as improved air quality, rainfall runoff and flooding levels, and noise reduction (Nowak and Dwyer, 2007).

In residential settings, indoor water usage remains relatively stable throughout the year and is largely correlated with household size and appliance efficiency (Gregory and Leo, 2003; Syme et al., 2004). In fact, residential areas account for $\approx 50 \%$ of urban water usage (Hayden et al., 2015). Outdoor water use is most often determined by garden type, importance and size, and social norms. Watering gardens, lawns, and landscapes is considered to be a discretionary use as compared with indoor water use, and conspicuous outdoor water use is often a prime target for regulation (Jorgensen et al., 2009). Homeowners frequently irrigate more than what is essential for their landscape because they lack knowledge about irrigation requirements (Hayden et al., 2015).

From 2001 to 2011, consumers' attitudes toward water conservation have become more positive and this change in attitudes is followed somewhat by behavioral shifts in water usage (Beal et al., 2013). Despite the change in attitudes, a Gallup poll showed that only $5 \%$ of respondents said water conservation has become a part of a lifestyle change (shopping and living habits) to protect the environment (Jones, 2008). Beal et al. (2013) examined perceived water usage as compared with actual water usage. Households that were informed about their areas of water usage were more accurate in evaluating water usage in their household, as compared with households who had little knowledge about their water usage and assumed their usage level. When given information about their actual water usage, households with inaccurate water assumptions made changes to their future water usage (Seyranian et al., 2015).

Throughout the United States, waterintensive landscapes are beginning to be replaced by water-efficient and climateappropriate landscapes (Hurd, 2006). Changing water use behavior involves several social and economic factors. For example, water preferences are not only a function of water prices and conservation motives but also time constraints, knowledge on how to conserve, and monetary restrictions. Attempting to change preferences may produce longer term responses for landscape water use that will reduce future water demand (Hurd, 2006).

Gilg and Barr (2006) found that many homeowners perceive their gardens require at least a minimum amount of water for plants to survive the summer. In their Australian study conducted to determine attitudes about conservation and water consumption, $25 \%$ of homeowner respondents reported watering their gardens three to four times weekly and even disregarded permitted levels of watering. At the same time, another $24 \%$ of homeowner respondents reported never watering their gardens but relied on rainfall. Outdoor water usage was observed by apartment dwellers to decrease, where $36 \%$ said the gardens around their buildings were never watered (Randolph and Troy, 2008). The most common practices made by homeowners to conserve residential water use were reducing garden watering and taking shorter showers (Randolph and Troy, 2008).

\section{Demographic Characteristics and Water Use}

Demographic characteristics also influence water usage and conservation. Low water users were older, less educated, and had lower incomes compared with high water users (Beal et al., 2013). Gilg and Barr (2006) also found that individuals who were considered nonenvironmentalists tended to be male, younger, received lower income, had less formal education, and less involved in the community. Increasing income level was directly related to an increase in water consumption (Mini et al., 2014; Renwick and Archibald, 1998). Households with a yearly income $>\$ 100,000$ practiced water conservation more frequently and were more likely to include drought-tolerant plants into their landscape, indicating an income tipping point (Fan et al., 2017). This was also substantiated by Helfand et al. (2006), Loss et al. (2009), and Worthington and Hoffman (2008), who found that more affluent consumers were more willing to pay for eco-friendly landscape plants. Boyer et al. (2015) even found that higher income households $(>\$ 75,000)$ were more likely to adopt indoor and outdoor water conservation practices than lower income households $(<\$ 40,000)$.

Being female is also positively correlated with the adoption of drought-tolerant plants and more favorable attitudes toward water conservation and environmentalism (Fan et al., 2017; Gilg and Barr, 2006). In fact, male head-of-households were $20 \%$ less likely to adopt drought-tolerant plants (Fan et al., 2017).

Although age is an indicator of conservation behavior, increased knowledge and education seem to be more directly linked to 
adoption strategies (Gilg and Barr, 2006; St. Hilaire et al., 2010). Households with lower water use had a greater sense of conservation issues, local concerns, and future preservation of water resources (Gregory and Leo, 2003).

Based on the literature, we hypothesized that (H1) not all consumers perceive drought accurately, (H2) some consumers will reduce or eliminate landscape purchases during periods of drought, and (H3) consumer perceptions about drought differ with regard to their drought status. Data to support or refute these hypotheses will have important consequences for the horticulture industry. Findings could inform educational extension and undergraduate programs, nursery producers in production decisions, and marketing strategies used by retailers. The findings could also bolster marketing efforts to encourage sustainable planting of lower water use cultivars around country during low water availability conditions. Our goal was to better understand consumer attitudes and behavior during real and perceived drought, especially in terms of their landscape purchases and gardening/landscaping activities in different regions of the United States.

\section{Materials and Methods}

We developed an online survey instrument following widely cited market research protocols to ensure greater degree of accuracy and speed, whereas reducing human error and survey expenses (Cobanoglu et al., 2001; Dillman et al., 2009; McCullough, 1998). The instrument included questions regarding a wide variety of topics related to plant and water use including plant purchases and expenditures, attitudes about water conservation and landscape plants, knowledge about water conservation and landscape plants, and demographic characteristics. The content and formatting of the survey questions were adapted from Behe et al. (2013, 2015) and Syme et al. (2004). The protocol and instrument were approved by the university committee on research involving human subjects (Michigan State University IRB\# x16-1053e Category: Exempt 2). We used SPSS version 24 and SAS version 9.4 to make a series of F-test comparisons for the percentage of subjects with landscape space available and irrigation areas and percentage of plant purchases for each of the four groups identified. We also employed a one-way analysis of variance in SAS version 9.4 to make comparisons of demographic characteristics.

The use of online surveys can have disadvantages, especially if the sampling database is comprised of the same panelist under different accounts. To alleviate this concern, the researchers contracted with a company, Lightspeed Global Marketing Insite (Warren, NJ), which maintains a panel of $\approx 1.3$ million persons and has control mechanisms in place to eliminate duplicate panelists. They identified a random sample of individuals $\geq 18$ years of age and distributed invitations. The survey was administered from 7 to 13 Sept., 2016, to 5769 potential participants. Subjects were directed to answer four quality assurance checkpoints in a specific manner. This was to insure that respondents were reading every question. Our goal was to obtain at least 100 responses for one chronic drought state (California) and one nondrought state (Wisconsin) and the remaining responses from the other U.S. states.

We defined areas of drought using data from the National Drought Mitigation Center (Heim, 1999). This metric is used to classify levels of drought experienced at any given time across the contiguous United States. The U.S. Drought Monitor Drought Conditions maps for 20 Sept. 2016 and 15 Sept. 2015 were chosen because of consumer's likelihood of awareness of current drought conditions when the survey was administered (Sept. 2016) and from the previous year (Sept. 2015).

We classified subjects into one of four groups to analyze how real and perceived drought affected attitudes and behavior related to plant purchases and water usage. We used the question, "Were you in an area that experienced drought this year?" to assess their perception of drought. We then compared their response with the drought monitor classifications to assess whether they correctly perceived being (or not being) in drought and then classified them into one of four categories: "Perceived/Real" included respondents who correctly perceived a drought when they actually experienced real drought conditions $(\mathrm{P} / \mathrm{R})$; the second category was "Not Perceived/Real" for subjects who did not perceive drought conditions but actually experienced them $(\mathrm{NP} / \mathrm{R})$; the third category was described as "Perceived/Not Real" for subjects who perceived a drought when their area actually did not experience a drought $(\mathrm{P} / \mathrm{NR})$; and the fourth category was identified as "Not Perceived/Not Real" for subjects who did not perceive a drought nor experienced one (NP/NR).

We hypothesized that consumers were heterogeneous in their attitudes and behavior regarding plants and water conservation, depending on their real and perceived drought situations, and that their attitudes affect their behavior regarding plant purchases. For example, subjects classified in the $\mathrm{P} / \mathrm{R}$ category may show a different attitude about water conservation and behavior, especially compared with subjects in NP/NR category who may not be as concerned about water use. Individuals in the NP/NR category would be described as "in normal

Table 1. Mean and SD of seven demographic characteristics of respondents to a water-related survey of households in 2016 that were in a real drought situation and correctly perceived it $(\mathrm{P} / \mathrm{R})$; in a real drought situation but did not perceive it (NP/R); and not in a real drought situation and did not perceive it (NP/NR).

\begin{tabular}{|c|c|c|c|c|}
\hline Characteristic & $\mathrm{P} / \mathrm{R}(n=252)$ & $\mathrm{NP} / \mathrm{R}(n=803)$ & $\mathrm{NP} / \mathrm{NR}(n=448)$ & Significance level \\
\hline Age & $57.46(15.39) \mathrm{ab}$ & $55.87(17.25) \mathrm{b}$ & $58.73(16.68) \mathrm{a}$ & $P=\mathbf{0 . 0 1 4}$ \\
\hline Adults in household & $1.08(0.88)$ & $1.21(0.902)$ & $1.19(0.88)$ & $P=0.158$ \\
\hline Plant-related expenditures 2015 & $\$ 107.78(\$ 125.06) \mathrm{a}$ & $\$ 120.88(\$ 133.44) a b$ & $\$ 131.96(\$ 146.42) b$ & $P=\mathbf{0 . 0 7 7}$ \\
\hline Plant-related expenditures 2016 & $\$ 105.28(\$ 124.70)$ & $\$ 117.80(\$ 132.06)$ & $\$ 127.08(\$ 135.91)$ & $P=0.112$ \\
\hline
\end{tabular}

Statistically significant coefficients $(P$ values $<0.10)$ are presented in bold. Different letters within rows indicate statistically significant differences. Analyses were generated using the GLIMMIX procedure of SAS software (SAS for Windows, v 9.4; SAS Institute Inc., Cary, NC).

Table 2. F-test comparison of percentage of subjects with landscape space available and irrigation areas of respondents to a water-related survey of households in 2016 that were in a real drought situation and correctly perceived it $(\mathrm{P} / \mathrm{R})$; in a real drought situation but did not perceive it $(\mathrm{NP} / \mathrm{R})$; and not in a real drought situation and did not perceive it (NP/NR).

\begin{tabular}{|c|c|c|c|c|c|}
\hline & Total $(n=1,467)$ & $\mathrm{P} / \mathrm{R}(n=252)$ & $\mathrm{NP} / \mathrm{R}(n=803)$ & NP/NR $(n=448)$ & Significance level \\
\hline \multicolumn{6}{|l|}{ Space available } \\
\hline Patio Porch & 15.2 & 17.4 & 14.6 & 13.3 & $P=0.281$ \\
\hline Neither & 7.0 & 5.5 & 7.4 & 8.1 & $P=0.340$ \\
\hline Irrigate landscape beds & 25.0 & $34.7 \mathrm{a}$ & $23.8 \mathrm{~b}$ & $11.8 \mathrm{c}$ & $P<0.001$ \\
\hline
\end{tabular}

Statistically significant coefficients $(P$ values $<0.01)$ are presented in bold. Different letters within rows indicate statistically significant differences. Analyses were generated using the GLIMMIX procedure of SAS software (SAS for Windows, v 9.4; SAS Institute Inc.). 
Table 3. F-test comparison of percentage of plant purchases of respondents to a water-related survey of households in 2016 that were in a real drought situation and correctly perceived it $(\mathrm{P} / \mathrm{R})$; in a real drought situation but did not perceive it $(\mathrm{NP} / \mathrm{R})$; and not in a real drought situation and did not perceive it $(\mathrm{NP} / \mathrm{NR})$.

\begin{tabular}{|c|c|c|c|c|c|}
\hline Plant type & Total $(n=1,504)$ & $\mathrm{P} / \mathrm{R}(n=252)$ & $\mathrm{NP} / \mathrm{R}(n=803)$ & $\mathrm{NP} / \mathrm{NR}(n=448)$ & Significance level \\
\hline Annual & 49.9 & 49.4 & 49.7 & 51.2 & $P=0.897$ \\
\hline Vegetable & 41.4 & 41.7 & 40.0 & 45.2 & $P=0.356$ \\
\hline Herb & 30.3 & 30.9 & 31.3 & 25.8 & $P=0.244$ \\
\hline Perennial & 29.9 & 29.8 & 29.4 & 31.4 & $P=0.828$ \\
\hline Flowering shrub & 19.2 & 18.5 & 19.6 & 19.0 & $P=0.905$ \\
\hline Evergreen shrub & 7.4 & $9.8 \mathrm{a}$ & $6.5 \mathrm{~b}$ & $6.0 \mathrm{ab}$ & $P=\mathbf{0 . 0 7 3}$ \\
\hline Fruit tree & 9.3 & 9.2 & 9.4 & 8.9 & $P=0.957$ \\
\hline Evergreen tree & 6.9 & $8.2 \mathrm{a}$ & $7.2 \mathrm{ab}$ & $3.6 \mathrm{~b}$ & $P=0.074$ \\
\hline Shade tree & 7.6 & 9.6 & 6.7 & 6.8 & $P=0.158$ \\
\hline
\end{tabular}

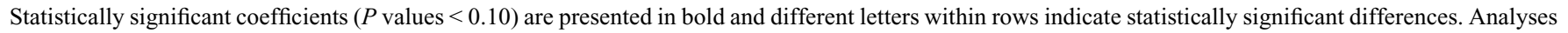
were generated using the GLIMMIX procedure of SAS software (SAS for Windows, v 9.4; SAS Institute Inc.)

Table 4. Mean and SD for attitudinal measures of respondents to a water-related survey of households in 2016 that were in a real drought situation and correctly perceived it (P/R); in a real drought situation but did not perceive it (NP/R); and not in a real drought situation and did not perceive it (NP/NR). Mean scores are based on a 5 -point Likert scale where $0=$ strongly disagree and $5=$ strongly agree.

\begin{tabular}{|c|c|c|c|c|}
\hline & $\mathrm{P} / \mathrm{R}(n=252)$ & $\mathrm{NP} / \mathrm{R}(n=803)$ & $\mathrm{NP} / \mathrm{NR}(n=449)$ & Significance leve \\
\hline I think that WC is important & $4.37(0.832) \mathrm{b}$ & $4.45(0.769) \mathrm{b}$ & $4.66(0.615) \mathrm{a}$ & $P=0.000$ \\
\hline I think that WC is of great concern to me & $4.03(0.944) \mathrm{a}$ & $4.15(0.886) \mathrm{ab}$ & $4.36(0.615) \mathrm{b}$ & $P=\mathbf{0 . 0 0 0}$ \\
\hline I know a lot about WC & $2.70(1.062) \mathrm{c}$ & $2.90(1.064) b$ & $3.07(1.028) \mathrm{a}$ & $P=\mathbf{0 . 0 0 0}$ \\
\hline I conserve water in and around my home & $3.47(1.116) \mathrm{c}$ & $3.67(1.020) \mathrm{b}$ & $3.93(0.913) \mathrm{a}$ & $P=\mathbf{0 . 0 0 0}$ \\
\hline I use fixtures that help me conserve water at home & $3.15(1.197) \mathrm{b}$ & $3.27(1.157) b$ & $3.50(1.117) \mathrm{a}$ & $P=\mathbf{0 . 0 0 0}$ \\
\hline $\begin{array}{l}\text { The price of water restricts what I can do in the landscape } \\
\text { areas outside my home }\end{array}$ & $2.42(1.236) \mathrm{b}$ & $2.53(1.279) \mathrm{b}$ & $2.88(1.355) \mathrm{a}$ & $P=\mathbf{0 . 0 0 0}$ \\
\hline $\begin{array}{l}\text { In a water crisis, we should not buy or try to maintain } \\
\text { outdoor landscape plants }\end{array}$ & $3.19(0.927)$ & $3.16(0.986)$ & $3.27(1.011)$ & $P=0.200$ \\
\hline $\begin{array}{l}\text { I have decreased my outdoor plant purchases due to water } \\
\text { restrictions in my neighborhood }\end{array}$ & $2.01(1.004) \mathrm{b}$ & $2.17(1.044) b$ & $2.59(1.220) \mathrm{a}$ & $P=\mathbf{0 . 0 0 0}$ \\
\hline
\end{tabular}

Statistically significant coefficients $(P$ values $<0.01)$ are presented in bold. Different letters within rows indicate statistically significant differences. Analyses were generated using the GLIMMIX procedure of SAS software (SAS for Windows, v 9.4; SAS Institute Inc.). WC = water conservation.

conditions." Respondents in the P/NR category may show similar attitudes and behavior to the individuals in the $\mathrm{P} / \mathrm{R}$ because they perceived a drought, even though they really were not experiencing one. The NP/R respondents were of interest because those respondents lacked knowledge about the real drought occurring in their area and could be using water excessively. We hypothesized that subjects classified as NP/NR were different demographically, spent more on plants (because they may not have known they faced water restrictions), and engaged in less water conservation behavior compared with other groups. This could result from $P / R$ subjects having concerns in the first seasons to get landscape plants established.

\section{Results and Discussion}

Completed surveys that passed the four quality assurance checks totaled 1543 or $\approx 26.7 \%$ of the recruited subjects. All U.S. states were represented except Hawaii. The mean age of respondents was 40 years $( \pm 16.87)$ and they were predominately female $(57.8 \%)$. Mean household size was 1.2 adults and 0.43 children. Respondents were primarily Caucasian (87\%), followed by African American (3\%), Hispanic (3\%), Asian (2.7\%), and Native American, Pacific Islander, and other races ( $2 \%)$. About a third $(28.3 \%)$ earned a 4-year college degree followed by $21 \%$ of respondents who had completed some college. Less than 1.2\% had a high school diploma or less. The majority of the respondents (59.8\%) lived in residential neighborhoods and their mean
2016 household income was $\$ 60,000$ $\$ 79,999$. All states except for Hawaii were represented (incidental to data collection). We strived to include at least 100 respondents from chronic drought areas such as California and at least 100 respondents from nondrought states such as Wisconsin in the sample.

As compared with the 2016 U.S. Population Census (U.S. Census Bureau, 2017) from 2010 to 2015 , our survey respondents represent a similar distribution. Census data indicate that the mean household income was $\$ 79,263$. Total U.S. population was $\approx 323$ million with 125.82 million households with an average household size of 2.6 people. Racially, the population was $77 \%$ Caucasian, 13.3\% African American, 17.6\% Hispanic, 5.6\% Asian, and $1.4 \%$ Native American, Pacific Islander, or other races. Nationally, $29.8 \%$ of Americans had a bachelor's degree or more education. Females represented $50.8 \%$ of the population and the median age was 37.9 years(U.S. Census Bureau, 2017).

Butterfield and Baldwin (2015) reported that the average home spent $\$ 401$ on lawn and garden, up from $\$ 317$ in 2014. The largest segment Butterfield and Baldwin (2015) identified, Food Gardening, captured $36 \%$ of the consumer expenditures, followed by flower garden purchases at $34 \%$. The largest portion of the 90 million households ( $75 \%$ of total U.S. households) who participated in lawn and garden activities had an income of $\$ 75,000$ or more, were mostly female, aged 55 years and older, and had earned a bachelor's degree. Nearly one-third (28\%) of households purchased their plants from home centers whereas $29 \%$ bought plants from mass merchandisers (Butterfield and Baldwin, 2015). Without variances, it is not possible to compare the current sample with the Census and National Gardening Association (Butterfield and Baldwin, 2015) samples, but they appear to be similar in respect to variables normally affecting final demand (e.g., age, incomes, etc.).

We conducted a chi square test to examine the percentage of subjects whose drought conditions changed from 2015 to 2016 . We found that $<3 \%$ experienced a change $(P<$ $0.0001)$, indicating that most of the subjects experienced a similar drought situation based on real drought condition changes from 2015 to 2016 . Of the total useful responses, $16.4 \%$ were in the group $\mathrm{P} / \mathrm{R}$ (correctly perceiving they were in a drought situation), $29.1 \%$ were in the group NP/NR (correctly perceiving they were not in drought), $52.3 \%$ were classified in the group NP/R (incorrectly perceiving they were not in drought), and only $2.0 \%$ were in the $\mathrm{P} / \mathrm{NR}$ group (incorrectly perceiving they were in drought). Because the NP/NR were accurate in their perception that they did not experience a drought, this group may serve as a "control" or "benchmark" against which to compare the other groups. Those in the $\mathrm{P} / \mathrm{R}$ were accurate in that they perceived a drought when they were really in a drought situation. But their attitudes and behavior may be different from the NP/NR group who were also correct in their perceptions. Given the small number of respondents in P/NR group, they were excluded from this part of the analysis. The P/NR group actively participated in water conserving behaviors when 
they would not have needed to. They were removed because they represented such a small portion of the sample The NP/R group represented an interesting subset of the sample frame in that they were in a drought situation, but did not perceive it. We hypothesized that their purchasing behaviors and attitudes might differ from the other two groups (P/R and NP/NR).

Demographically, the three groups were similar on five of the seven characteristics (Table 1). Subjects in NP/NR were nearly 3 years older than those in the NP/R group, but similar to subjects in the $\mathrm{P} / \mathrm{R}$ drought area. There were no differences among the respondents in terms of gender, income, and the number of adults/children in the household. There was a difference, however, in their plant-related expenditures. Subjects in $\mathrm{P} / \mathrm{R}$ spent $\$ 24.18$ less $(\approx 18 \%)$ on plants and related supplies in 2015 compared with expenditures for those in NP/NR group. These differences were consistent with prior work (Gilg and Barr, 2006; St. Hilaire et al., 2010).

Participants in all three groups had a similar percentage of individuals with a lawn and landscape, and patio/porch area, as well as those who had neither (only $7 \%$ overall) (Table 2). However, a higher percentage of participants in the $\mathrm{P} / \mathrm{R}$ category irrigated turfgrass or irrigated landscape beds. Those who irrigated turfgrass areas ranged from $13.0 \%$ for the NP/NR respondents to $35.2 \%$ for the $\mathrm{P} / \mathrm{R}$ group. Those who irrigated landscape beds ranged from $11.8 \%$ for $\mathrm{NP} /$ NR respondents to $34.7 \%$ for $\mathrm{P} / \mathrm{R}$ respondents. The higher level of irrigation for the $\mathrm{P} / \mathrm{R}$ group compared with the NP/NR group may reflect the possibility that the $\mathrm{P} / \mathrm{R}$ group would not otherwise have turfgrass or landscape plants if they did not irrigate them. This would be consistent with the finding that a higher percentage of the NP/R group irrigated turfgrass and landscape beds more compared with the NP/NR group.

We asked what types of plants were purchased in 2016 (Table 3) and found that annuals were the dominant plant category purchased (by $49.8 \%$ of the respondents overall), followed by vegetables $(41.6 \%)$, herbs $(30.5 \%)$, perennials $(29.7 \%)$, and flowering shrubs (19.2\%), respectively. A much smaller percentage of subjects in each category had purchased evergreen shrubs $(7.4 \%$ overall), fruit trees $(9.3 \%)$, evergreen trees $(6.8 \%)$, and shade trees $(7.5 \%)$. Very few differences between the groups were observed, with each of the three groups exhibiting similar percentages of purchases for annuals, perennials, flowering shrubs, and fruit trees. However, a higher percentage of the $\mathrm{P} / \mathrm{R}$ group purchased evergreen trees and shrubs compared with the other two groups. The higher incidence of purchase for evergreen shrubs and trees for those who correctly perceived drought during real drought conditions may partly be explained in that the evergreens may require less water to establish after transplanting.
Attitudinally, we found differences between the three groups (Table 4). When asked whether they thought water conservation was important, all three groups had a high mean score, indicating their agreement with the statements and a general importance about water conservation. However, we found a higher level of agreement, generally, in the NP/NR. This mean level of agreement was higher compared with both $\mathrm{P} / \mathrm{R}$ and NP/R. A similar pattern was found when asked if water conservation was of great concern. When asked if they "know a lot about water conservation" and if they "conserved water in and around their home," there were differences among all three groups with the $\mathrm{P} / \mathrm{R}$ group ranking the lowest, interestingly. Both the $\mathrm{P} / \mathrm{R}$ and NP/R groups were lower than the NP/NR group for three of the attitudinal questions including "I use fixtures that help me conserve water at home," "The price of water restricts what I can do in the landscape areas outside my home," and "I have decreased my outdoor plant purchases due to water restrictions in my neighborhood." The only question in which there were no differences stating "In a water crisis, we should not buy or try to maintain outdoor landscape plants" with all three groups moderately agreeing with this statement.

This difference in attitude observed among the groups may be partly explained by the Hierarchy of Competency (Adams, 2017). Although we expected $P / R$ to be most sensitive to drought conditions, this would not necessarily be true by the "order of recognition." Individuals begin as unconsciously incompetent and are initially unaware of what they do not know. The theory then posits that they gradually recognize they have a knowledge deficit, to knowing how to handle the knowledge deficiency. They may further develop to unconscious competency where the "skill" or knowledge is second nature. What we conclude from these results is that subjects in the $\mathrm{P} / \mathrm{R}$ group likely demonstrate the consciously competent by being aware of the drought and having knowledge to adjust their lifestyles or being aware of their lack of knowledge or ability adjust to drought conditions. NP/R may demonstrate unconsciously incompetent, where they do not know the deficit of knowledge they lack and therefore are not sensitive to drought information and issues. Finally, NP/NR may demonstrate being consciously competent of their drought conditions. They recognize their drought status but it is also possible that they have experience in drought conditions or have prior knowledge and are sensitive to drought information and issues.

These attitudinal findings support those of Beal et al. (2013) regarding the degree to which social awareness and exposure to drought conditions affect attitudes toward water conservation. We speculate that maybe the more a person becomes aware of a drought the more they may realize they do not know. Beal et al. (2013) observed when people who are over- or underestimating their water usage are made aware of their actual water usage (education/awareness) they could change their habits. But, technology engineered to assist with water conservation needed to be tied to water conserving behavior-not used as a crutch. There is a paradox in which the more underestimating water consumers are made aware of their behavior, the more they realize they do not know.

\section{Conclusions}

Given the increasing importance of waterrelated issues across the United States, it is imperative to increase our understanding of how consumers view water conservation, especially related to the lawns and landscapes surrounding their homes. However, the evidence to date in the literature has been limited to a few states. In addition, we know relatively little about consumer behavior during real and perceived periods of drought, especially with respect to landscape plant purchases. As importantly, we do not know for sure if consumers perceive drought periods correctly, let alone whether they are likely to modify their landscape care and maintenance practices during periods of drought or if a drought influences their plant purchasing decisions at all. This study was developed to explore the answers to these questions, which will have important implications for the horticulture industry.

Our goal was to better understand consumer behavior during real and perceived drought situations, especially in terms of their landscape purchases and gardening/ landscaping activities. We hypothesized that consumers were heterogeneous in their attitudes and behavior regarding plants and water conservation, depending on their real and perceived drought situations, and that their attitudes affected their behavior regarding plant purchases. Findings from this study confirm this hypothesis. For example, subjects classified in the P/R category demonstrated a different attitude about water conservation and plant purchasing behavior, especially compared with subjects in the NP/NR category. More education is still needed to help facilitate the transition from intensively managed landscapes to include the use of plants or cultivars that use less water. Growers, wholesalers, and retailers will benefit from leading some of this change by promoting the water use needs of plants, especially those with lower use, and continuing to communicate water sources in plant production as well as landscape water needs.

\section{Literature Cited}

Adams, L. 2017. Learning a new skill is easier said than done. Gordon Training International, Solana Beach, CA. 9 Nov. 2017. <http://www. gordontraining.com/free-workplace-articles/ learning-a-new-skill-is-easier-said-than-done/> .

Akbari, H. 2005. Energy saving potentials and air quality benefits of urban heat island mitigation. Lawrence Berkeley National Laboratory, Berkeley, CA. 
Alfredo, K. 2016. America's water: Developing a road map for the future of our nation's infrastructure. Columbia Water Center, Columbia University, New York, NY. 13 Mar. 2017. <http://water.columbia.edu/2016/03/22/ americas-water-developing-a-road-map-forthe-future-of-our-nations-infrastructure/>.

Beal, C.D., R.A. Stewart, and K. Fielding. 2013. A novel mixed method smart metering approach to reconciling differences between perceived and actual residential end use water consumption. J. Clean. Prod. 60:116-128.

Behe, B.K., M. Bae, P.T. Huddleston, and L. Sage. 2015. The effect of involvement on visual attention and product choice. J. Retailing Consum. Serv. 24:10-21.

Behe, B.K., B.L. Campbell, C.R. Hall, H. Khachatryan, J.H. Dennis, and C. Yue. 2013. Consumer preferences for local and sustainable plant production characteristics. HortScience 48:209-215.

Boyer, T.A., P. Kanza, M. Ghimire, and J.Q. Moss. 2015. Household adoption of water conservation and resilience under drought: The case of Oklahoma City. Water Econ. Policy 1(02):1550005.

Butterfield, B. and I. Baldwin. 2015. National gardening survey. Natl. Gardening Assn., Williston, VT.

Cobanoglu, C., B. Warde, and P.J. Moreo. 2001. A comparison of mail, fax and web-based survey methods. Intl. J. Mkt. Res. 43:441-455.

Dillman, D., J. Smyth, and L. Christian. 2009. Internet, mail, and mixed-mode surveys: The tailored design method. Wiley, Hoboken, NJ.

Espey, M., J. Espey, and W.D. Shaw. 1997. Price elasticity of residential demand for water: A meta-analysis. Water Resources Res. 33(6):1369-1374.

Fan, Y., L. McCann, and H. Qin. 2017. Households' adoption of drought tolerant plants: An adaptation to climate change? J. Agr. Res. Econ. 42(2):236-254.

Gilg, A. and S. Barr. 2006. Behavioral attitudes towards water saving? Evidence from a study of environmental actions. Ecol. Econ. 57(3):400-414.
Gregory, G.D. and M.D. Leo. 2003. Repeated behavior and environmental psychology: The role of personal involvement and habit formation in explaining water consumption. J. Appl. Soc. Psychol. 33(6):1261-1296.

Hayden, L., M.L. Cadenasso, D. Haver, and L.R Oki. 2015. Residential landscape aesthetics and water conservation best management practices: Homeowner perceptions and preferences. Landsc. Urban Plan. 144:1-9.

Heim, R. 1999. United States Drought Monitor. The National Drought Mitigation Center, Lincoln, NE. 8 Feb. 2017. <http://droughtmonitor. unl.edu/>.

Helfand, G.E., J.S. Park, J.I. Nassauer, and S. Kosek. 2006. The economics of native plants in residential landscape designs. Landsc. Urban Plan. 78(3):229-240.

Hurd, B.H. 2006. Water conservation and residential landscapes: Household preferences, household choices. J. Agr. Res. Econ. 31(2):173-192.

Jones, J.M. 2008. In the U.S., 28\% report major changes to live "green." GALLUP. 7 Dec. 2016. <http://www.gallup.com/poll/106624/ us-28-report-major-changes-live-green.asp $\mathrm{x}>$.

Jorgensen, B., M. Graymore, and K. O’Toole. 2009. Household water use behavior: An integrated model. J. Environ. Mgt. 91(1):227-236.

Loss, S.R., M.O. Ruiz, and J.D. Brawn. 2009. Relationships between avian diversity, neighborhood age, income, and environmental characteristics of an urban landscape. Biol. Conserv. 142(11):2578-2585.

Maupin, M.A., J.F. Kenny, S.S. Hutson, J.K. Lovelace, N.L. Barber, and K.S. Linsey. 2014. Estimated use of water in the United States in 2010. U.S. Geological Survey Circular 1405:56. 15 Dec. 2016. <https://pubs. usgs.gov/circ/1405/>.

McCullough, D. 1998. Web-based market research: The dawning of a new age. Direct Mktg. 61:36-38.

Mini, C., T.S. Hogue, and S. Pincetl. 2014. Estimation of residential outdoor water use in Los Angeles, California. Landsc. Urban Plan. 127:124-135.

Nowak, D.J. and J.F. Dwyer. 2007. Understanding the benefits and costs of urban forest ecosystems, p. 25-46. In: J.E. Kuser (ed.). Urban and community forestry in the northeast. Springer, Dordrecht, The Netherlands.

Randolph, B. and P. Troy. 2008. Attitudes to conservation and water consumption. Environ. Sci. Policy 11(5):441-455.

Renwick, M.E. and S.O. Archibald. 1998. Demand side management policies for residential water use: Who bears the conservation burden? Land Econ. 74(3):343-359.

Seyranian, V., G.M. Sinatra, and M.S. Polikoff. 2015. Comparing communication strategies for reducing residential water consumption. J. Environ. Psychol. 41:81-90.

Somerville, C. and J. Briscoe. 2001. Genetic engineering and water. Science 292(5525):2217.

Spinti, J.E., R.S. St. Hilaire, and D. VanLeeuwen. 2004. Balancing landscape preferences and water conservation in a desert community. HortTechology 14:72-77.

Springer, A.C. 2011. Creating water conscious communities: An examination of household water conservation in a decade of drought. Univ. Arizona, Tucson, AZ, PhD Diss. Abstr. 10150-205213.

St. Hilaire, R.S., M.A. Arnold, D.C. Wilkerson, D.A. Devitt, B.H. Hurd, B.J. Lesikar, and D.R. Pittenger. 2008. Efficient water use in residential urban landscapes. HortScience 43:20812092.

St. Hilaire, R.S., D.M. Van Leeuwen, and P. Torres. 2010. Landscape preferences and water conservation choices of residents in a high desert environment. HortTechology 20:308314.

Syme, G.J., Q. Shao, M. Po, and E. Campbell. 2004. Predicting and understanding home garden water use. Landsc. Urban Plan. 68:121128.

U.S. Census Bureau. 2017. American FactFinder. U.S. Dept. Commerce. 08 Feb. 2017. <https:// factfinder.census.gov/faces/tableservices/jsf/ pages/productview.xhtml?pid=ACS_15_5YR_ DP05\&src $=\mathrm{pt}>$.

Worthington, A.C. and M. Hoffman. 2008. An empirical survey of residential water demand modelling. J. Econ. Surv. 22(5):842-871. 